\title{
REPRODUCIBILITY OF PALM-BASED POLYOLS PRODUCTION
}

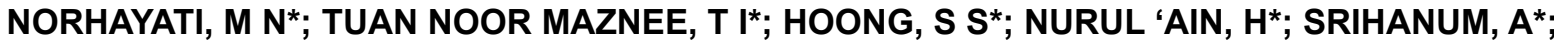 \\ KOSHEELA DEVI, P P*; MOHD NORHISHAM, ${ }^{*}$; YEONG, $\mathrm{S} \mathrm{K}^{*}$ and HAZIMAH, A H*
}

\begin{abstract}
The purpose of this article is to verify the reproducibility of palm-based polyols from the optimised reaction conditions. The reproducibility studies on the production of the palm-based polyols were conducted via alcoholysis of epoxidised palm olein with isobutanol, catalysed by K10 montmorillonite under the optimised reaction conditions (reaction temperature at $60^{\circ} \mathrm{C}$ for $2 \mathrm{hr}$ ). It was proven that palm-based polyols with similar properties can be repeatedly produced when a set of standard synthesis steps was followed. This indicates that palm-based polyol can be produced with specific range of properties and this enables a feasible commercial production of palm-based polyols. The study on the recyclability of used K10 montmorillonite in the production of palm-based polyols will be carried out in the future.
\end{abstract}

Keywords: palm-based polyols, alcoholysis, K10 montmorillonite, reproducibility.

Date received: 26 January 2015; Sent for revision: 30 January 2015; Received in final form: 1 October 2015; Accepted: 13 January 2016.

\section{INTRODUCTION}

Vegetable oils such as soyabean, rapeseed, castor and palm oils play an important part in renewable resources. The abundance and low cost industrialscale production make natural vegetable oils and their derivatives the most significant renewable resources in the chemical industry (Lligadas et al., 2013; Zieleniewska et al., 2014). Palm-based polyol is one of the examples of vegetable-based chemical that is used as raw materials for many applications such as in the making of polyurethane (PU) foams, adhesives and elastomers (Nurul 'Ain et al., 2014; Ang et al., 2014). Many studies have been conducted in order to produce these vegetable-based polyols from the natural sources (Abraham, 2012; Arniza et al., 2015). These efforts are important in providing solutions to effectively produce polyols with the desired properties.

\footnotetext{
* Malaysian Palm Oil Board,

6 Persiaran Institusi, Bandar Baru Bangi,

43000 Kajang, Selangor, Malaysia.

E-mail: norhayati.mohdnoor@mpob.gov.my
}

The most common method to prepare polyols from vegetable oils is through epoxidation of alkene groups of triglycerides to yield epoxidised vegetable oils. The epoxidised vegetable oils are then subjected to alcoholysis with polyhydric alcohols to yield the desired polyols (Hazimah et al., 2011). The reaction schemes of epoxidation of refined, bleached and deodorised (RBD) palm olein and alcoholysis of epoxidised RBD palm olein (EPOo) to produce palm-based polyol are described in Figure 1.

The EPOo was produced on pilot plant scale by reacting the RBD palm olein with hydrogen peroxide $\left(\mathrm{H}_{2} \mathrm{O}_{2}\right)$ and formic acid $(\mathrm{HCOOH})$. In the present study, the EPOo was reacted with isobutanol in the presence of $\mathrm{K} 10$ montmorillonite catalyst to produce palm-based polyol.

Alcoholysis is one of the chemical processes that can be applied for the production of palm-based polyols. Several homogeneous catalysts such as formic acid, phosphoric acid, $p$-toluene sulphonic acid monohydrate ( $p$-TSA) and acid-blocked version of $70 \%$ bis(dimethylaminoethyl) ether with $30 \%$ dipropylene glycol (DABCO®BL 17) have been used in the oxirane ring opening reaction of 

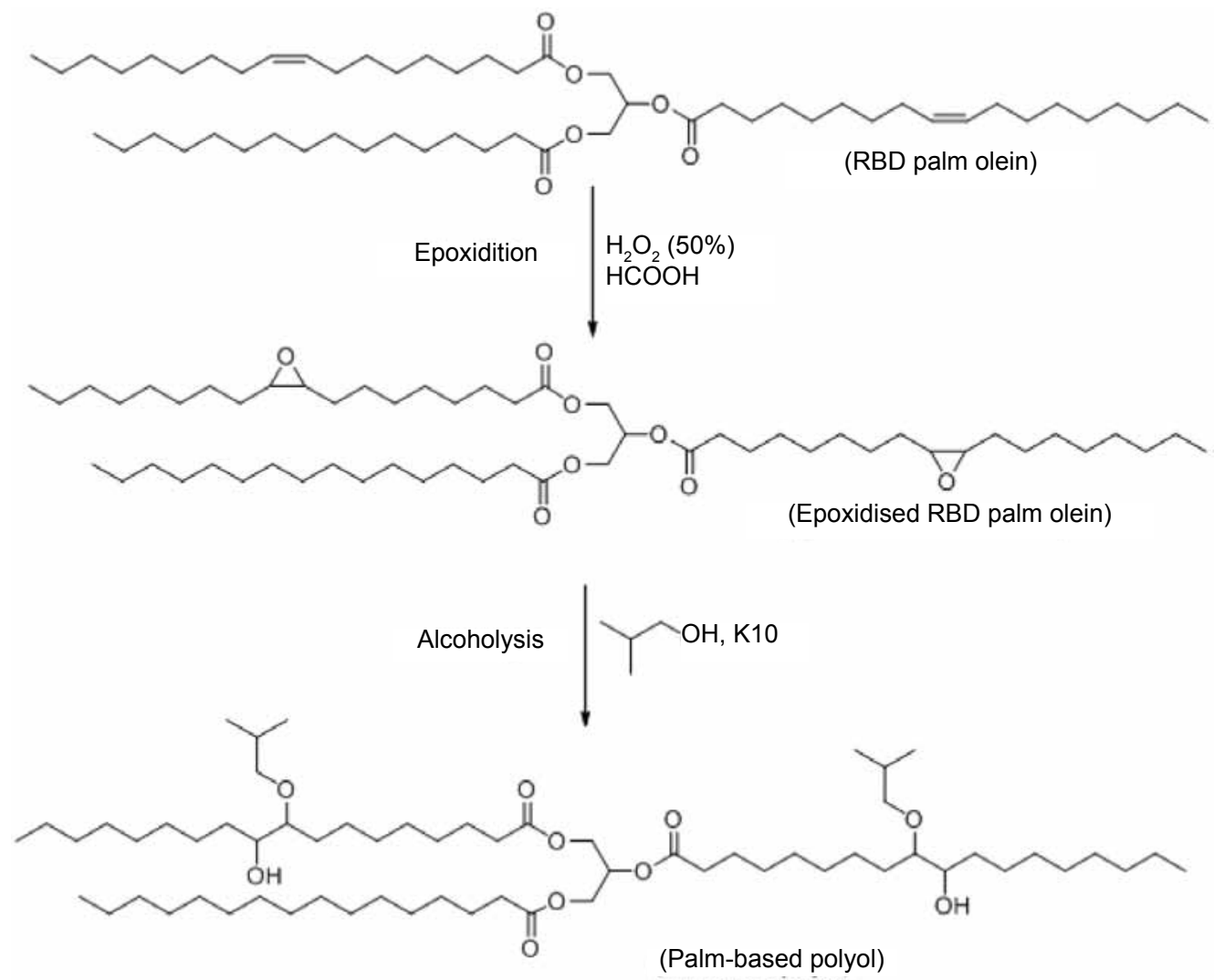

Idealised structure

Figure 1. Reaction schemes in epoxidation of refined bleached deodorised (RBD) palm olein and alcoholysis of epoxidised RBD palm olein (EPOo) to produce palm-based polyol.

natural epoxidised oil. Among the catalysts used in the Lozada's study, $p$-TSA showed a high catalytic reactivity that promotes the ring opening reaction which gives a maximum reduction of oxirane oxygen content (OOC), i.e., $5.95 \%$ from $7.0 \%$ of the initial OOC of epoxidised oil. However, $p$-TSA requires high reaction temperature, i.e., $150^{\circ} \mathrm{C}$ for oxirane ring opening reaction (Lozada et al., 2009). Boron trifluoride-diethylether complex catalyst is commonly used in alcoholysis process in order to produce palm-based polyol. The oxirane ring of epoxidised palm oil was opened by nucleophilic addition of a polyhydric alcohol. The temperature of the alcoholysis was between $60^{\circ} \mathrm{C}$ to $100^{\circ} \mathrm{C}$, in which the OOC was reduced to $0.01 \%$. A purifying step was required in the process to clean the chemical residue in the produced polyols after the alcoholysis process (Hazimah et al., 2011).

On the other hand, uses of heterogeneous catalysts have increased in importance since they can simplify the process and provide a cleaner process compared to homogeneous catalyst (Norhayati et al., 2013). Clay catalyst is one of the heterogeneous catalysts and has been reported to be able to promote the alcoholysis of epoxide group. The K10 montmorillonite is a subgroup of the smectite clay, where it has been recognised to be a very selective catalyst for a wide range of organic transformations which promotes the environmental benign green chemistry. In addition to this interesting characteristic of clay catalyst, its price is relatively low compared to other heterogeneous catalysts and this combination of good properties and price makes it an attractive catalyst for industrial applications (Rios et al., 2003).

Clay catalyst has a special nature, that it can function as both Brønsted and Lewis acid in their natural and ion-exchanged form. The montmorillonite lattice is composed of a sheet of octahedrally coordinated gibbsite $\left[\mathrm{Al}_{2}(\mathrm{OH})_{6}\right]$ sandwiched between two sheets of tetrahedrally coordinated silicate $\left[\mathrm{SiO}_{4}\right]^{4-}$ sheets (Figure 2). The three-sheet layer repeats itself, and the interlayer space holds the key to the chemical and the physical properties of the clay. The Brønsted acid sites are mainly associated with inter-lamellar region and the Lewis acid with the edge sites. The Brønsted acid character arises mainly due to the dissociation of the intercalated water molecules coordinated to cations (Nagendrappa, 2002).

In this study, K10 montmorillonite catalyst was used in the production of palm-based polyols 

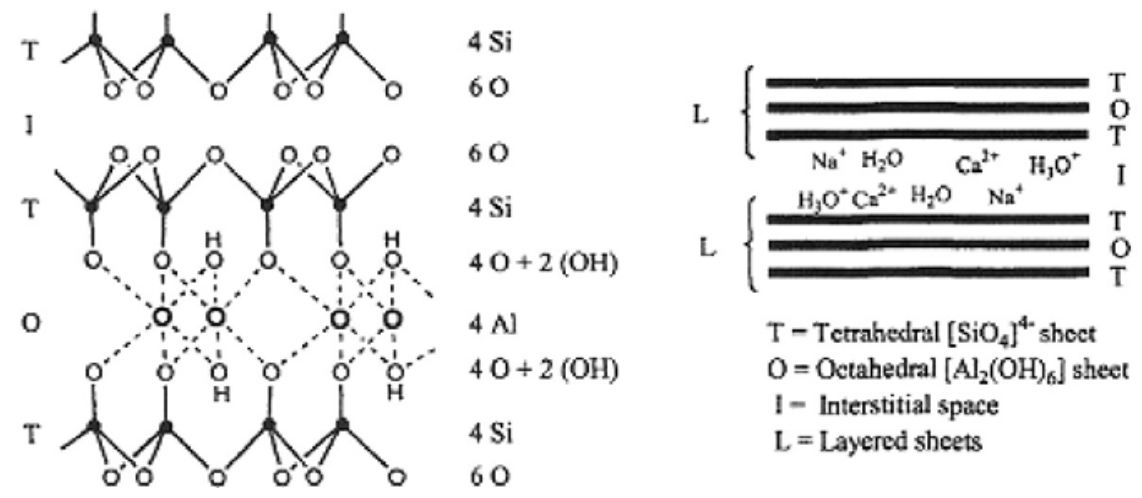

Figure 2. Structure of K10 montmorillonite.

via alcoholysis of epoxidised palm olein with isobutanol. The alcoholysis conducted with optimised parameters (reaction temperature at $60^{\circ} \mathrm{C}$ for $2 \mathrm{hr}$ ) showed that the OOC was reduced from $3.2 \%$ to $0.04 \%$. The properties of palm-based polyols can be reproduced if it was synthesised according to the optimised reaction conditions. The purpose of this work is to verify the reproducibility of palmbased polyol from the optimised reaction conditions.

\section{MATERIALS AND METHODS}

\section{Materials}

The EPOo was obtained from the Malaysian Palm Oil Board (MPOB) polyol pilot plant [specification: acid value $=0.4 \mathrm{mg} \mathrm{KOH} \mathrm{g}^{-1}$, iodine value $=$ $0.8 \mathrm{~g} \mathrm{I}_{2} 100 \mathrm{~g}^{-1}, \mathrm{OOC}=3.2 \%$, weight average molecular weight $(\mathrm{Mw})=1000$ Dalton and viscosity at $25^{\circ} \mathrm{C}$ $=127.0 \mathrm{mPa} . \mathrm{s}$ ]. Isobutanol and acetone of analytical reagent grade were purchased from Fisher Scientific (United Kingdom). The raw materials such as EPOo and isobutanol were dried prior to alcoholysis. The moisture content of the dried EPOo and isobutanol were $0.03 \%$ and $0.07 \%$, respectively. The K10 montmorillonite catalyst was purchased from FlukaChemica (Germany). It was used without further modification.

\section{Methods}

Preparation of palm-based polyols. Dried EPOo was reacted with dried isobutanol in the presence of K10 montmorillonite catalyst at $60^{\circ} \mathrm{C}$ for $2 \mathrm{hr}$. Reactions were carried out in a $500 \mathrm{ml}$ reaction flask placed in an oil bath. A polytetrafluoroethylene (PTFE) coated stainless steel shaft, and an anchor flat propeller were used for stirring. In this reaction, $10 \mathrm{~g}$ of K10 montmorillonite catalyst was premixed with 154 $\mathrm{g}(2.1 \mathrm{~mol})$ of isobutanol at $60^{\circ} \mathrm{C}$ for $15 \mathrm{~min}$ before adding $100 \mathrm{~g}(0.2 \mathrm{~mol})$ of EPOo. The isobutanol was used in excess. The reaction was allowed to take place under continuous stirring for $2 \mathrm{hr}$. After $2 \mathrm{hr}$ of reaction, the OOC of the reaction mixture was less than $0.05 \%$ which indicated the completion of the reaction. The obtained reaction mixture was cooled down to room temperature $\left(23^{\circ} \mathrm{C}\right)$. Five replicates of palm-based polyols were prepared using the optimised reaction conditions in order to verify the reproducibility of the resultant polyols.

\section{Preparation of PB Polyols}

PB is a benchmark palm-based polyol which was prepared in the laboratory. It was obtained from the alcoholysis of dried EPOo with dried isobutanol in the presence of $\mathrm{K} 10$ montmorillonite catalyst at $60^{\circ} \mathrm{C}$ of reaction temperature for $2 \mathrm{hr}$. Reaction was carried out in a $500 \mathrm{ml}$ reaction flask placed in an oil bath. A PTFE coated stainless steel shaft, and an anchor flat propeller were used for stirring. In this reaction, $10 \mathrm{~g}$ of $\mathrm{K} 10$ montmorillonite catalyst was pre-mixed with $154 \mathrm{~g}(2.1 \mathrm{~mol})$ of isobutanol at $60^{\circ} \mathrm{C}$ for $15 \mathrm{~min}$ before adding $100 \mathrm{~g}(0.2 \mathrm{~mol})$ of EPOo. The isobutanol was used in excess. The reaction was allowed to take place under continuous stirring for $2 \mathrm{hr}$. After $2 \mathrm{hr}$ of reaction, the OOC of the reaction mixture was less than $0.05 \%$ which indicated the completion of the reaction. The obtained reaction mixture was cooled down to room temperature $\left(23^{\circ} \mathrm{C}\right)$.

\section{Separation, Distillation and Drying of Reaction Products}

Approximately, $100 \mathrm{ml}$ of acetone was added into the reaction mixture in order to ease the separation of K10 montmorillonite catalyst from the reaction mixture. The separation process was conducted using a vacuum filtration (Watmann filter paper No. 5). Distillation process was carried out in order to remove the excess isobutanol and acetone in the reaction product. A $500 \mathrm{ml}$ three-necked 
round bottom flask containing the filtered reaction mixture was placed in an oil bath, equipped with a reflux condenser and a vacuum pump. A magnetic bar was used for stirring. At temperature of $115^{\circ} \mathrm{C}$ and $80 \mathrm{mbar}$ of vacuum pressure, the isobutanol and acetone should be removed out from the reaction product within 5 to $6 \mathrm{hr}$. As a precautionary step, the obtained reaction product was dried under vacuum (9.43 mbar) in order to ensure excess isobutanol and acetone was totally removed. The drying temperature was at $115^{\circ} \mathrm{C}$. The drying process was stopped when the moisture content of the reaction product was below $0.05 \%$ and the smell of isobutanol and acetone were not detected.

\section{Characterisation of Palm-based Polyols}

The OOC of the reaction mixture was determined following the American Oil Chemists Society (AOCS) Official Method Cd 9-57 (AOCS, 2007). The moisture content of the palm-based polyols was measured by using C30 Karl Fischer coulometer with Hydranal Coulomat-AG as an anolyte. The acid value $(\mathrm{AV})$ was analysed according to AOCS Official Method Te 2a-64. The hydroxyl value (OHV) and the iodine value (IV) were determined according to the AOCS Official Method Cd 13-60 (pyridine-acetic acid anhydride titration method) and the AOCS Official Method Cd 1d-92 (cyclohexane-acetic acid titration method), respectively. The viscosity was determined using a Brookfield Digital Rheometer, Model DV-III +. The Fourier transform infrared (FTIR) spectra were determined using Perkin Elmer FTIR Spectrum 100 Mild DTIR. The infrared spectra were recorded as liquid in the range of 650 to 4000 $\mathrm{cm}^{-1}$. The molecular weight was measured using a Varian PL-gel permeation chromatography (GPC) 50 Plus equipped with a differential refractive index (DRI)/viscometer (combined detector). The molecular weights of the samples were analysed using a PLGel Mixed D column. Tetrahydrofuran (THF) stabilised with $250 \mathrm{ppm}$ butylated hydroxytoluene (BHT) was used as the eluent and the flow rate was fixed at $1.00 \mathrm{ml} \mathrm{min}^{-1}$. The molecular weight distributions were obtained based on a calibration curve generated from polystyrene (PS) standards.

\section{RESULTS AND DISCUSSION}

The success of the alcoholysis process depends on the readiness of the epoxide group to be ringopened by addition of a nucleophilic alcohol to the epoxide. Generally, alcohols are weak nucleophiles, therefore, their addition to epoxides demand the pre-activation of the epoxide (Rios et al., 2005). The epoxide can be protonated by a Brønsted acid present in the catalyst. Then, the activated epoxide would be ring-opened by an alcohol in the system via $S_{N} 2$ mechanism (Figure 3) (Rios et al., 2003).

By following the practiced method, the same chemical reaction should occur and produce the desired palm-based polyols. In this reproducibility study, five replicates samples of palm-based polyols namely R1, R2, R3, R4 and R5 were prepared. Table 1 shows the properties of the prepared palm-based polyols and $\mathrm{PB}$.

The $\mathrm{pH}$ of all prepared palm-based polyols was in the range of $\mathrm{pH} 5$ to $\mathrm{pH} 6$, which was slightly acidic. The colour of all the samples was slightly yellowish. At each hour of reaction, a small amount of reaction mixture was collected for OOC analysis. Result from the analysis showed that the OOC was drastically reduced after $1 \mathrm{hr}$ of reaction time and gradually decreased as the reaction time increased. The OOC of the prepared palm-based polyols were in the range of $0.03 \%$ to $0.04 \%$, which showed that more than $90 \%$ conversions of epoxide group to hydroxyl group in the palm-based polyols were obtained, within $2 \mathrm{hr}$ of reaction period. It was preferred to have a fast reaction rate in order to avoid the crosslinking between epoxide with the polyol, which can lead to the formation of by-products.

As shown in Table 1, the IV of all the palm-based polyols were in the range of 12.0 to $16.0 \mathrm{~g} \mathrm{I}_{2} 100 \mathrm{~g} \mathrm{~g}^{-1}$. The IV expresses the unsaturation content of the polyol. The excess of isobutanol used in the reaction was to prevent the polymerisation reaction, which can cause the formation of branched polymer in the produced palm-based polyol. The acid value $(\mathrm{AV})$ of the palm-based polyols were in the range of 0.8 to $1.2 \mathrm{mg} \mathrm{KOH} \mathrm{g}^{-1}$ and OHV between 74.0 to $94.0 \mathrm{mg}$ $\mathrm{KOH} \mathrm{g}^{-1}$. The AV describes the free fatty acid content present in the polyol. Generally, the AV of polyol is influenced by the hydrolysis process. The hydrolysis can occur when a polyol is in contact with water under acidic condition, for example during the
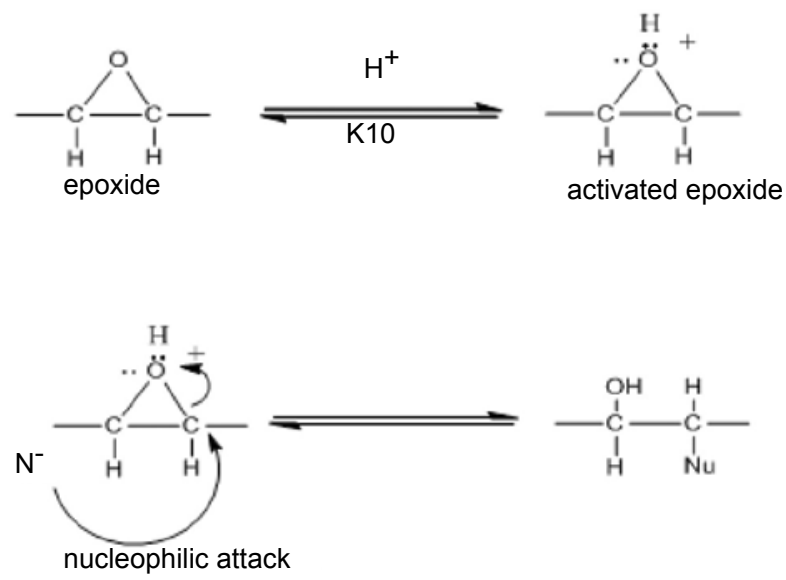

Figure 3. Activation of epoxide and ring-opened by nucleophilic in alcohol $\left(\mathrm{Nu}^{-}=\right.$nucleophile $)$. 
TABLE 1. PROPERTIES OF THE PREPARED PALM-BASED POLYOLS

\begin{tabular}{|c|c|c|c|c|c|c|c|c|c|c|}
\hline Properties & PB & R1 & R2 & R3 & R4 & R5 & AVG & SD & UCL & LCL \\
\hline $\begin{array}{l}\text { Oxygen oxirane content, } \\
\text { OOC }(\%)\end{array}$ & 0.04 & 0.03 & 0.04 & 0.03 & 0.03 & 0.04 & 0.035 & 0.005 & 0.05 & 0.02 \\
\hline Moisture content, $(\%)$ & 0.05 & 0.04 & 0.05 & 0.04 & 0.05 & 0.05 & 0.047 & 0.005 & 0.06 & 0.03 \\
\hline $\begin{array}{l}\text { Iodine value, IV } \\
\left(\begin{array}{ll}\mathrm{g} \mathrm{I}_{2} & \left.100 \mathrm{~g}^{-1}\right)\end{array}\right.\end{array}$ & 16.0 & 13.5 & 13.2 & 12.2 & 15.3 & 13.1 & 13.883 & 1.452 & 18.24 & 9.53 \\
\hline $\begin{array}{l}\text { Acid value, } \mathrm{AV} \\
\left(\mathrm{mg} \mathrm{KOH} \mathrm{g}^{-1}\right)\end{array}$ & 1.0 & 0.8 & 0.9 & 0.8 & 1.2 & 1.0 & 0.950 & 0.152 & 1.41 & 0.50 \\
\hline $\begin{array}{l}\text { Hydroxyl value, OHV } \\
\left(\mathrm{mg} \mathrm{KOH} \mathrm{g}^{-1}\right)\end{array}$ & 88.6 & 84.9 & 86.4 & 93.7 & 73.9 & 76.9 & 84.067 & 7.406 & 106.28 & 61.85 \\
\hline Viscosity, mPa.s@ $25^{\circ} \mathrm{C}$ & 465.9 & 603.7 & 475.6 & 567.8 & 577.6 & 611.5 & 550.350 & 63.800 & 741.75 & 358.95 \\
\hline GPC (Mw), Dalton & 1500 & 1600 & 1600 & 1600 & 1500 & 1600 & 1566.667 & 51.640 & 1721.59 & 1411.75 \\
\hline GPC (PDI), Dalton & 1.4 & 1.6 & 1.5 & 1.5 & 1.5 & 1.5 & 1.500 & 0.063 & 1.69 & 1.31 \\
\hline
\end{tabular}

Note: $\mathrm{Mw}=$ weight average molecular weight, $\mathrm{PDI}=$ polydispersity index, $\mathrm{AVG}=$ average, $\mathrm{SD}=$ standard deviation, $\mathrm{UCL}=$ upper control limits, $\mathrm{LCL}=$ lower control limits, (Reaction condition: temperature $=60^{\circ} \mathrm{C}$, duration $=2 \mathrm{hr}$, molar ratio of epoxide: isobutanol $=0.2$ mol:2.1 mol and catalyst, $\mathrm{K} 10=10 \mathrm{~g}$ )

neutralisation process. In this study, the prepared palm-based polyols gave low AV because no neutralisation was required in the practiced method. The hydroxyl value (OHV) measures the amount of hydroxyl groups in the polyol. The hydroxyl group is a major requirement needed in the calculation to formulate PU products.

Based on the calculated upper control limits (UCL) and lower control limits (LCL) (Table 1), it showed that the obtained properties of $\mathrm{PB}$ and prepared palm-based polyols fall within the control limits. These analyses proved that the utilisation of the optimised reaction conditions with K10 montmorillonite catalyst can generate polyols with consistent properties.

Figure 4 shows the spectra of EPOo, PB and prepared palm-based polyols (R1 to R5). All spectra were recorded from 650 to $4000 \mathrm{~cm}^{-1}$. The EPOo's spectrum shows the absence of hydroxyl group at $3470 \mathrm{~cm}^{-1}$ and the presence of epoxide group at 820 to $860 \mathrm{~cm}^{-1}$. The polyol's molecules were described by $\mathrm{PB}$ and prepared palm-based polyols spectra where it had adsorbed frequencies that showed the characteristics of the palm-based polyol structure. All the polyol samples showed the presence of hydroxyl absorption at about $3470 \mathrm{~cm}^{-1}$ and the absence of an epoxide group at 820 to $860 \mathrm{~cm}^{-1}$. The absorption peak of ketone group from 1705 to 1725 $\mathrm{cm}^{-1}$ was not observed in the spectra. This indicated that the reactions were occurred without undesirable side-reactions.

GPC was used to determine the molecular weight of the prepared palm-based polyols. The molecular weight of all the prepared palm-based polyols were within the range of 1500 to 1600 Dalton and their polydispersity indices were in between 1.4 to 1.6. The low polydispersity indices represent homogeneity of the prepared palm-based polyols. Based on the properties for all the prepared palm-based polyols, they strongly show that the reproducibility of palm-based polyol is very good.

\section{CONCLUSION}

The reproducibility study of the palm-based polyol production was successfully carried out. It was proven that the palm-based polyols with similar properties can be reproduced from the optimised reaction conditions (reaction temperature at $60^{\circ} \mathrm{C}$ for $2 \mathrm{hr}$ ). It also indicates that by following the practiced method, palm-based polyol can be produced and controlled within the same range of quality. In the future, the study on the recyclability of used K10 montmorillonite catalyst in the production of palmbased polyols can be carried out.

\section{ACKNOWLEDGEMENT}

The authors would like to thank the DirectorGeneral of MPOB for permission to publish this article. The authors also would like to thank the research assistants of the Advanced Oleochemicals Technology Division, MPOB for their technical support. 


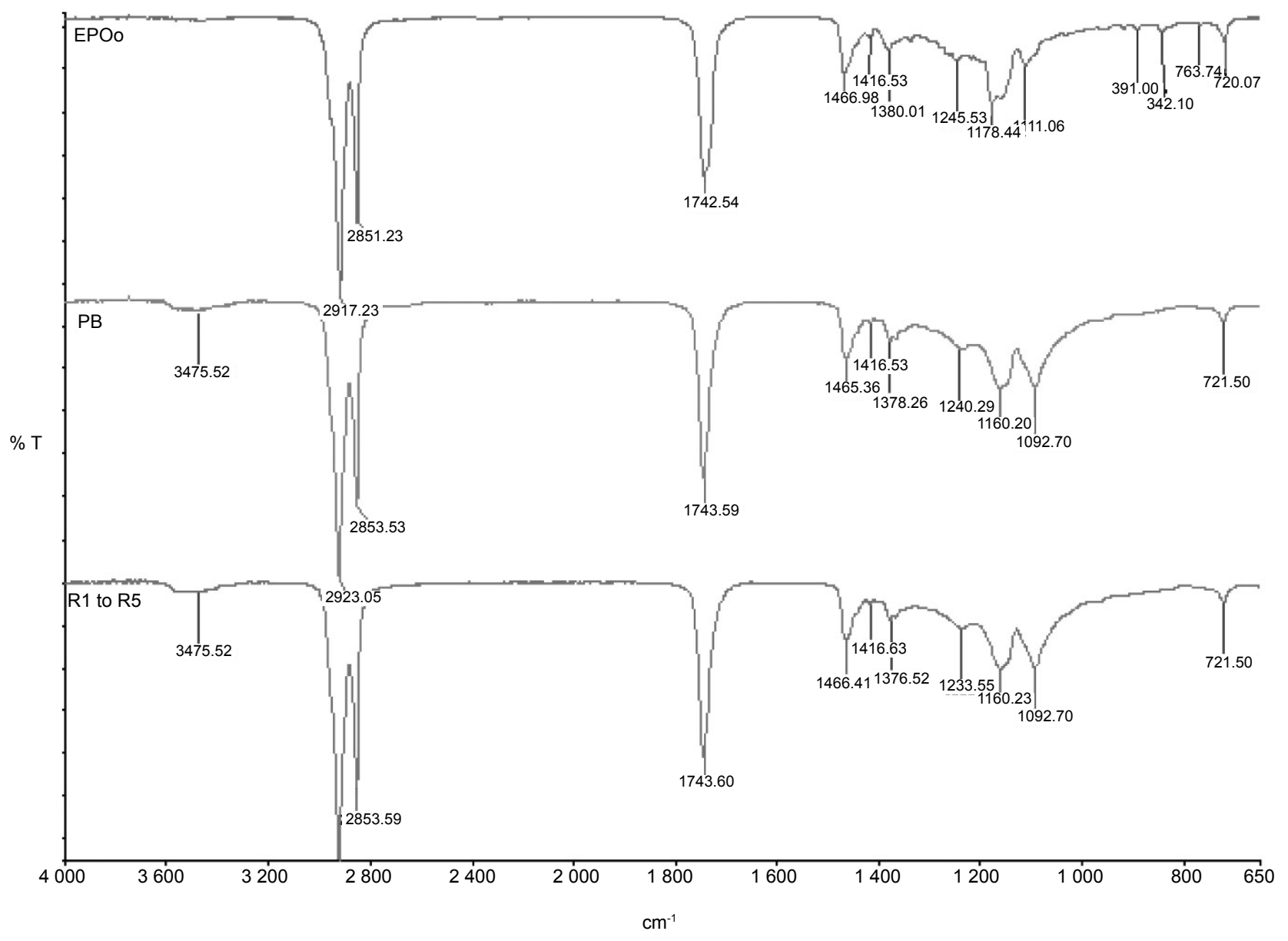

Figure 4. The Fourier transform infrared (FTIR) spectra of epoxidised palm olein (EPOo), PB and prepared palm-based polyols (R1 to R5).

\section{REFERENCES}

ABRAHAM, T W (2012). Chapter II: Advances in the use of $\mathrm{BiOH}{ }^{\circledR}$ polyols in polyurethane. Biobased Monomers, Polymers and Materials. ACS Symposium Series, American Chemical Society, Washington, DC. p. 165-181. DOI: $10.1021 /$ bk-2012-1105.ch011.

AOCS (2001). Section C: sampling and analysis of commercial fats and oils (reapproved 1997). Official Methods and Recommended Practices of the AOCS. Fifth edition.

ARNIZA, M Z; HOONG, S S; IDRIS, Z; YEONG, S K; HASSAN, H A; DIN, A K and CHOO, Y M (2015). Synthesis of transesterified palm olein-based polyol and rigid polyurethane from this polyol. J. Amer. Oil Chem. Soc., 92: 243-255. DOI: $10.1007 /$ s11746-0152592-9.

ANG, K P; LEE, C S; CHENG, S F and CHUAH, C $\mathrm{H}$ (2014). Polyurethane wood adhesive from palm-based polyester polyol. J. Adhesion Science and Technology, 28(11):1020-1033. DOI: 10.1080/01694243.2014.883772.
HAZIMAH, A H; TUAN NOOR MAZNEE, T I; MOHD NORHISHAM, S; HOONG, S S; OOI, T L; SALMIAH, A; KOSHEELA DEVI, P P and CHEONG, M Y (2011). Process to produce polyols. US patent 7,932,409 B2. www.google.com/patents/US7932409

LLIGADAS, G; RONDA, J C; GALIA, $\mathrm{M}$ and CADIZ, V (2013). Renewable polymeric materials from vegetable oils: a perspective. Mater Today, 16(9): 337-343. DOI: 10.1016/j.mattod.2013.08.016.

LOZADA, Z; SUPPES, G J; TU, Y C and HSIEH, F H (2009). Soy-based polyols from oxirane ring opening by alcoholysis reaction. J. Applied Polymer Science, 113: 2552-2560. DOI: 10.1002 / app.30209.

NAGENDRAPPA, G (2002). Organic synthesis using clay catalysts. Resonance: J. Science Education, 7(1): 6477. DOI: $10.1007 /$ BF02836172

NORHAYATI, M N; TUAN NOOR MAZNEE, T I; YEONG, S K and HAZIMAH, A H (2013). Synthesis of palm-based polyols: effect of K10 montmorillonite catalyst. J. Oil Palm Res. Vol. 25(1): 92-99. Jopr.mpob. gov.my/synthesis-of-palm-based-polyols-effect-ofK10-montmorillonite-catalyst/?v=true 
NURUL 'AIN, H; TUAN NOOR MAZNEE, T I; MOHD. NORHISHAM, S; KOSHEELA DEVI, P P; NORHAYATI, M N; SRIHANUM, A; MOHD AZMIL, M N; ZAILAN, A B; YEONG, S K; HAZIMAH, A H and SENDIJAREVIC, V (2014). Viscoelastic foams having high dissipation energy. Malaysia application patent No. PI2014701601.

RIOS, L A; WECKES, P P; SCHUSTER, H; HAUSMANN, H and HÖLDERICH, W F (2003). Modification and characterization of aluminosilicates used for nucleophilic addition of alcohols to epoxidized oils. Applied Catalysis A: General, 253 (2): 487-497. DOI: 10.1016/S0926-860X(03)00547-7.
RIOS, L A; WECKES, P P; SCHUSTER, $\mathrm{H}$ and HÖLDERICH,WF(2005). Resincatalyzed alcoholysis of epoxidized fatty esters: effect of the alcohol and the resin structures. Applied Catalysis A: General, 284: 155-161. DOI: 10.1016/j.apcata.2005.01.031.

ZIELENIEWSKA, M; AUGUŚCIK, M; PROCIAK, A; ROJEK, P and RYSZKOWSKA, J (2014). Polyurethane-urea substrates from rapeseed oilbased polyol for bone tissue cultures intended for application in tissue engineering. Polymer Degradation and Stability, 108: 241-249. DOI: 10.1016/j. polymdegradstab.2014.03.010.

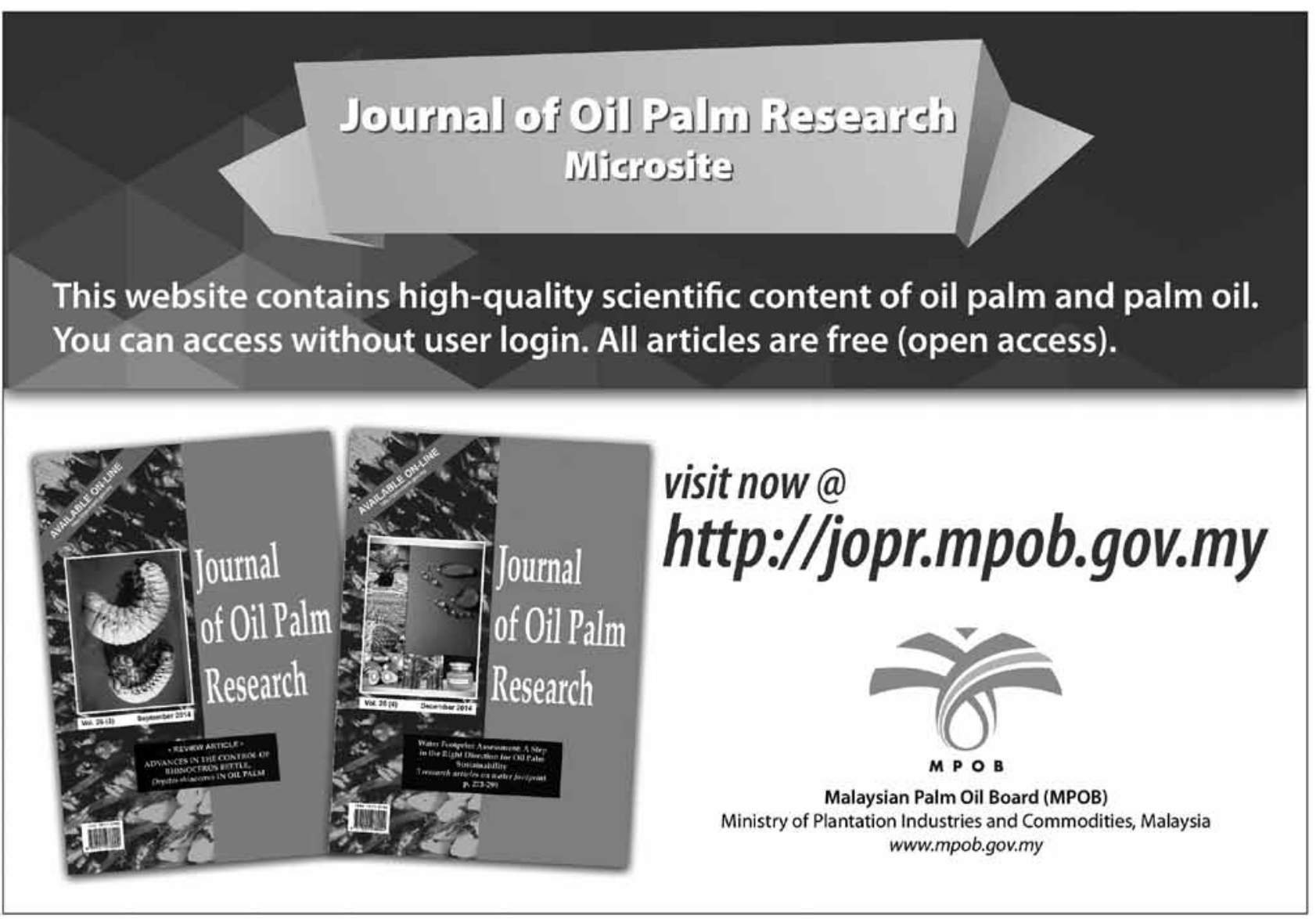

